\section{A rare cause of wheezing}

\author{
Alexander H. Cho, Jessica Logan, ${ }^{2}$ \\ Jalil Ahari' \\ 'Pulmonary/Critical Care Department, \\ Washington University, Washington, DC; \\ 2Department of Internal Medicine, DC VA \\ Medical Center, Washington, DC, USA
}

\begin{abstract}
A 24-year-old African American female nonsmoker, with a reported history of asthma presented to the hospital with 2 weeks of shortness of breath and sputum production. She had a chest X-ray and computed tomography scan that displayed evidence of a right upper lobe collapse. She subsequently had a bronchoscopy that revealed an endobronchial lesion at the opening of the right upper lobe bronchus. Biopsies performed were consistent with a granular cell tumor. Granular cell tumors are rare submucosal tumors of Schwann cell origin. Resection of the right upper lobe resolved her symptoms and wheezing.
\end{abstract}

\section{Case Report}

A 24-year-old African American female nonsmoker, with a reported history of asthma and no other medical history presented to the hospital with 2 weeks of diffuse body aches, shortness of breath and purulent sputum.

She was diagnosed clinically with asthma two years ago and reported daily usage of an albuterol inhaler with marginal response. Pulmonary function tests were not performed. Since diagnosis, she has been treated with antibiotics twice for bronchitis with her most recent episode two weeks prior to admission. Despite albuterol use and compliance with antibiotics, her symptoms have persisted.

On admission, physical exam was significant for inspiratory and expiratory wheezes in her right anterior chest. Laboratory studies revealed a white blood cell count of 9.02 with a normal eosinophil count and a normal metabolic panel. Given the focal nature of the patient's wheeze, imaging was deemed appropriate. A chest X-ray and computed tomography scan of the thorax showed right upper lobe collapse without any endobronchial or parenchymal lesions (Figure 1). In order to determine the cause of the right upper lobe collapse, we decided to proceed with bronchoscopy.

Bronchoscopy was performed which showed a nodular mass at the opening of her right upper lobe bronchus (Figure 2). We were unable to pass the bronchoscope around the lesion and only visualized the anterior branch of the upper lobe. A brush biopsy and 5 direct forceps biopsies were performed with minimal bleeding. Pathology revealed an abundance of large cells with highly granular cytoplasm (Figure 3). The immunohistochemical stains for S100, which is characteristically positive in schwannomas and other neural tumors, were diffusely positive (Figure 4). The brush biopsy did not reveal any malignant cells and the bronchial alveolar lavage showed few candida albicans and no bacterial growth. These findings were consistent with granular cell tumor.

The patient underwent a right upper lobe lobectomy 2 months after presentation. She was followed in clinic 1 month after her procedure and reported significant symptomatic improvement.

\section{Discussion}

Granular cell tumors (GCT) are rare submucosal tumors of Schwann cell origin. The median age of diagnosis for GCTs is 40 with a higher incidence in women and African Americans. ${ }^{1}$ They are found most commonly in the skin, subcutaneous tissue, oropharynx, and breast. However, approximately $6-10 \%$ of all GCTs are found in the lungs. ${ }^{2}$ In a review of 82 patients, Hernandez et al. found that $47 \%$ of lung GCTs were right sided, $42 \%$ were left sided, and $15 \%$ were within the trachea or carina. ${ }^{3}$ The symptoms associated with these endobronchial tumors include cough, hemoptysis, chest pain and recurrent infections. Biopsy is required for diagnosis, but unlike malignant endobronchial tumors, there is minimal bleeding with biopsy. GCTs are predominately benign with less than $2 \%$ being malignant. ${ }^{4}$ GCTs are mostly solitary, but multifocal disease has been reported. ${ }^{5}$ Treatment includes surgical resection, endoscopic removal and laser photocoagulation. The treatment of choice when associated post obstructive complications are seen is surgical resection, which makes recurrence unlikely. Benign GCTs can rarely recur locally when surgical resection is incomplete. ${ }^{5}$ When malignant, the lymph nodes, lungs, and bones are common sites of metastasis. ${ }^{6,7}$ Tsuchida et al. and Fanburg-Smith et al. report 50 and $41 \%$ mortality respectively by 2.8 to 3 years in metastatic disease. ${ }^{6,7}$

\section{Conclusions}

Granular cell tumors are rare, but should be considered when endobronchial lesions are encountered, especially in patients at a lower risk for malignancy.
Correspondence: Alexander H. Cho, Pulmonary/ Critical Care Department, Washington University, 2121 St NW, Washington, DC, USA. Tel: +1.202.741.2237.

E-mail: Cho.alexander.h@gmail.com

Conflict of interest: the authors declare no potential conflict of interest.

Key words: Wheezing; Granular cell tumor; Resection.

Received for publication: 14 April 2016.

Revision received: 27 July 2016.

Accepted for publication: 5 September 2016.

This work is licensed under a Creative Commons Attribution NonCommercial 4.0 License (CC BYNC 4.0).

\section{(C) Copyright A.H. Cho et al., 2016}

Licensee PAGEPress, Italy

Chest Disease Reports 2016; 4:5938

doi:10.4081/cdr.2016.5938
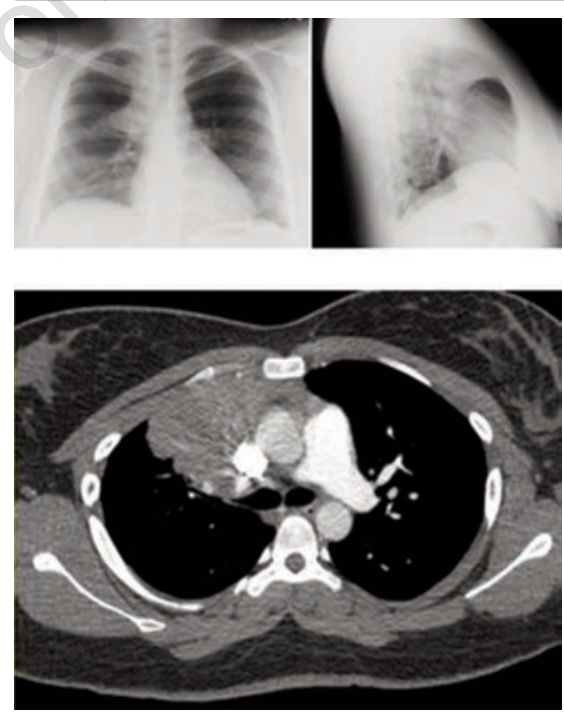

Figure 1. X-ray with opacification in the right upper lobe consistent with collapse. Computed tomography scan with an illdefined opacity in the right upper lobe with collapse of the right mainstem bronchus. Uniform density is consistent with collapsed lung.

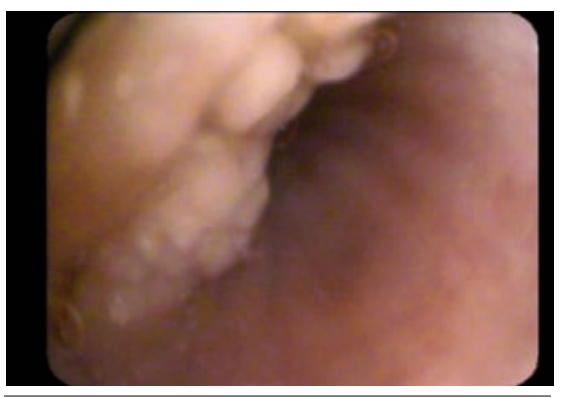

Figure 2. Nodular lesion obstructing the view at the opening of the right upper lobe bronchus. 


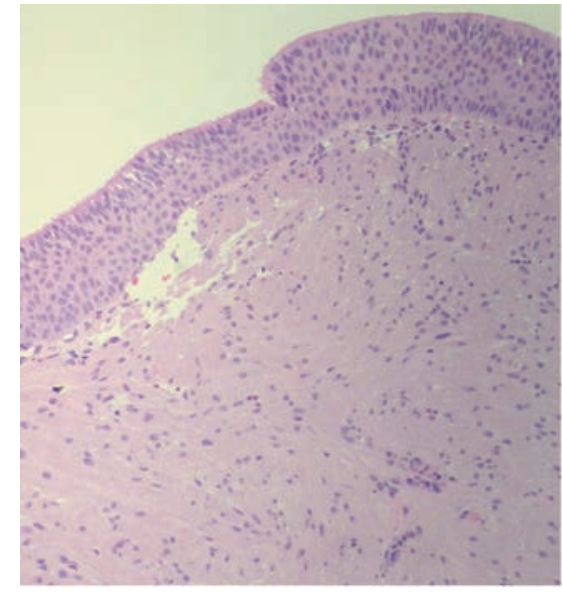

Figure 3. Pathology of the biopsied nodular lesion stained with hematoxylin and eosin displaying large cells with highly granular cytoplasm.

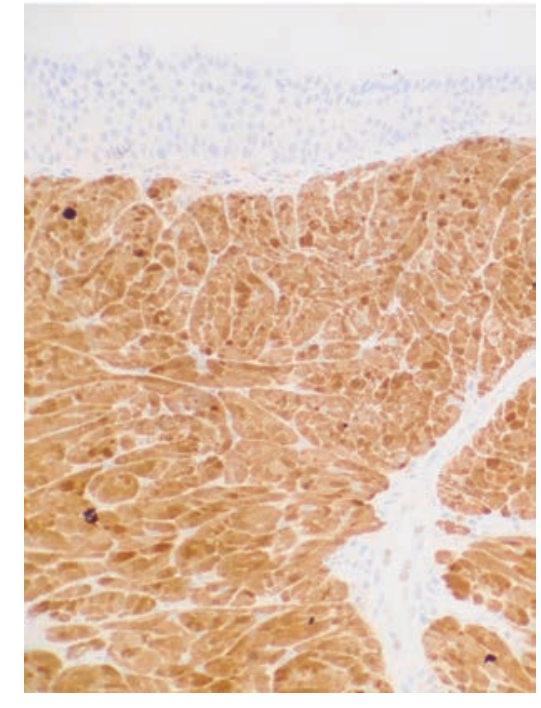

Figure 4. Pathology of biopsied nodular lesion which is diffusely positive when stained with S-100. S-100 is positive in neural tissue, the alternative diagnosis for a lesion with highly granular cytoplasm is carcinoid which is S-100 negative.

\section{References}

1. Vance III S, Hudson Jr R. Granular cell myoblastoma: clinicopathologic study of forty-two patients. Am J Clin Pathol 1969;52:208-11.

2. Deavers M, Guinee D, Koss M, Travis W. Granular cell tumors of the lung. Clinicopathologic study of 20 cases. Am J Surg Pathol 1995;19:627-35.

3. Hernandez 0, Haponik E, Summer W. Granular cell tumour of the bronchus: bronchoscopic and clinical features. Thorax 1986;41:927-31.

4. Goldblum J, Folpe A, Weiss S, et al. Enzinger and Weiss's soft tissue tumors. Amsterdam, The Netherlands: Elsevier; 2001.

5. Fanburg-Smith J, Meis-Kindblom J, Fante R, Kindblom L. Malignant granular cell tumor of soft tissue. Am J Surg Pathol 1998;22:779-94.

6. Goodstein M, Hyams D, Kashima H. Multiple synchronous granular cell tumors of the upper aerodigestive tract. Otolaryng Head Neck 1990;103:664-7.

7. Tsuchida $\mathrm{T}$, Okada $\mathrm{K}$, Itoi $\mathrm{E}$, et al. Intramuscular malignant granular cell tumor. Skeletal Radiol 1997;26:116-21. 